\title{
Adjustment of speed in repeated shifts of a negative reinforcer
}

\author{
RICHARD H. GRACELY and RUSSELL M. CHURCH \\ Brown University, Providence, Rhode Island 02912
}

\begin{abstract}
Four rats were trained to press a lever to escape from high-intensity $(.5 \mathrm{~mA})$ and low-intensity $(.25-\mathrm{mA})$ electric shock, and then the intensity of the shock was alternated in blocks of 30 trials within sessions. The animals escaped more rapidly from the high-intensity shock than from the low-intensity shock. Performance adjustments following an increase in shock intensity were rapid, while performance adjustments following an intensity decrease were more gradual. The asymptotic performance at constant shock intensity and the asymmetrical adjustment speeds following a shift in intensity were interpreted to be a result of a conflict between effort and reinforcement.
\end{abstract}

A simple escape response may be considered to be the resolution of a conflict between effort and reinforcement. The steady state escape latency, then, is the balance point between effort expenditure and reinforcement gain. If a particular escape latency is faster than the steady state level, the excessive effort will lead the next response to be somewhat slower; if a particular latency is slower than the steady state level, the increased duration of the electric shock will lead the next response to be somewhat more rapid.

Asymptotic response speed is increased by increasing the magnitude of the negative reinforcer. If the response terminates the shock, asymptotic response speed has been consistently shown to be positively related to the initial shock intensity (Boren, Sidman, \& Herrnstein, 1959; Nation, Wrather, \& Mellgren, 1974; Trapold \& Fowler, 1960). Even when the initial shock level is held constant, if the response reduces the shock, the asymptotic response speed has been shown to be negatively related to the final shock intensity (Bower, Fowler, \& Trapold, 1959).

A shift in the magnitude of the negative reinforcer typically results in an appropriate performance adjustment to a new asymptote (Bower et al., 1959; Nation et al., 1974). The present experiment concerns the rate at which postshift performance approaches a new asymptote. Relative speed of adjustment in previous experiments can be roughly estimated by determining the number of trials to asymptote for both upshifted and downshifted groups in the same experiment. If there is a difference between the groups in the speed of adjustment, the upward-shifted

This article is based on a thesis submitted by R. H. Gracely to Brown University in partial fulfillment of the requirements for the MS degree. The research was supported by research grants from the National Institute of Mental Health (MH-19704) and by the National Science Foundation (GB 43208). Requests for reprints should be made to $R$. $M$. Church, Department of Psychology. Brown University, Providence, Rhode Island 02912. R. H. Gracely's address is the National Institute of Dental Research, National Institutes of Health. groups reach asymptotic levels in fewer trials than the downshifted groups (Bower et al., 1959), but performance adjustment may be complete for both upshifted and downshifted groups after a few trials (Nation et al., 1974). These experiments only shifted once between the two magnitudes of negative reinforcement. Thus, the judgment regarding the relative speed of adjustment for upshifts and downshifts must be made from a small number of observations.

A more quantitative analysis of postshift adjustment could be obtained by the use of repeated shifts between two conditions of reinforcement. The present experiment involved blocks of 30 escape trials with the same shock intensity, and a large number of shifts between high and low intensity. This makes it possible to assess quantitatively the magnitude and speed of performance adjustment as a function of postshift trial.

Reinforcement was shock termination in a lever-escape task. This experiment was conducted in two phases. In the first phase, shock intensity was shifted between sessions to insure that the two intensity levels employed would lead to reliable escape responding with different asymptotic speeds. In the second phase, these shock intensity levels were repeatedly shifted within each experimental session.

\section{METHOD}

\section{Subjects}

The subjects were four male Norway albino rats (Charles River CD). They were approximately 180 days old at the beginning of the study and were maintained on an ad-lib diet of Purina Chow for the duration of the experiment.

\section{Apparatus}

The apparatus consisted of four identical lever boxes as described by Church, Raymond, and Beauchamp (1967). The aversive event was an electric shock delivered through a matchedimpedance source (150 Kohms in series) and scrambler (Lehigh Valley Electronics scanner, Model 1311) to the grid floor, the aluminum walls, and the lever. The experiment was controlled on-line by a time-shared PDP-12 computer. 


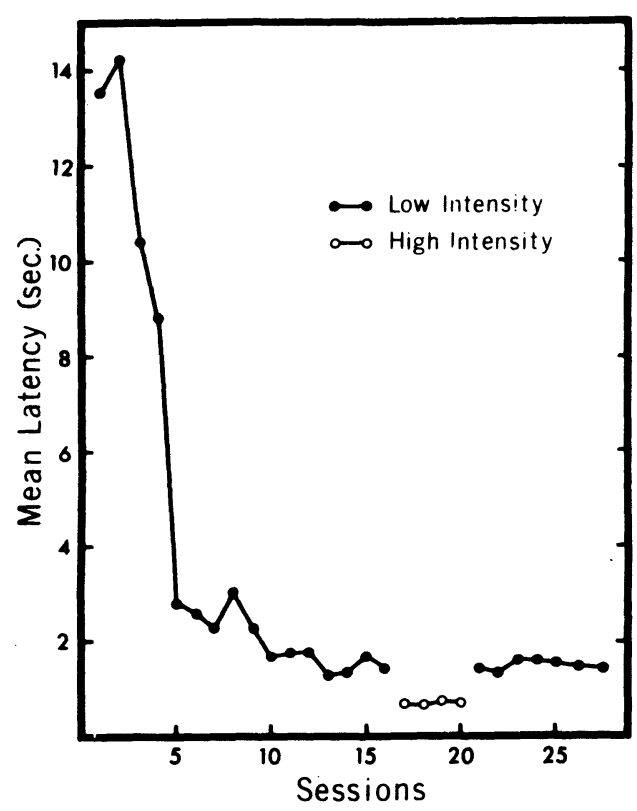

Figure 1. Geometric mean latency of escape for the four rats as a function of sessions. Shock intensity was .25 mA for Sessions 1-16, and Sessions 21-27. Shock intensity was increased to $.50 \mathrm{~mA}$ on Sessions 17.20.

Sessions were $2 \mathrm{~h}$ in length and were conducted 5 days per week at the same time each day. When a shock was presented, it was terminated by a single leverpress, or automatically after $30 \mathrm{sec}$ in the absence of a response. Following shock termination, there was an intertrial interval averaging $20 \mathrm{sec}$.

Escape training. Shocks of $.25-\mathrm{mA}$ intensity were delivered for 16 sessions. The shock intensity was increased to $.50 \mathrm{~mA}$ for four sessions and then restored to the original intensity for an additional seven sessions. Two additional animals which failed to acquire a stable escape response in the initial sessions were eliminated from the experiment.

Escape testing. During the next 16 sessions, shock intensity was shifted between the two previous values $(.25$ and $.50 \mathrm{~mA})$ within each session. The rats received 30 escape trials under the low intensity first, then the intensity was subsequently shifted every 30 trials for the remainder of the session. Typically, at least four full blocks of each intensity were completed in a single session by all subjects. The first block in each session was ignored, so that each block of low-intensity shock was followed by a block of high-intensity shock, and vice versa.

\section{RESULTS}

The geometric mean escape latencies during escape training are shown in Figure 1. Since the rats reliably escaped from both intensities, but at clearly distinguishable latencies, these two intensities were used in the secord part of the experiment.

Figure 2 shows the geometric mean latency as a function of trials for high- and low-intensity blocks averaged within and between sessions for each subject. All rats made an immediate and rapid adjustment following an intensity increase; three of the four rats made gradual adjustment following an intensity decrease.

\section{DISCUSSION}

A theoretical interpretation of these results must account for: (1) asymptotic performance at a constant shock intensity, and (2) asymmetrical adjustment speeds following a shift in shock intensity.

Presumably, an animal adjusts its escape latency to achieve a compromise between the goal of minimizing the severity of the shock and minimizing the effort of the response. To minimize the severity of a shock, the animal must respond quickly, since the severity of an electric shock increases as a function of its duration (Church, Raymond, \& Beauchamp, 19.67). On the other hand, to minimize the effort of a response, the animal must respond slowly. The actual escape latency may represent a compromise between these two opposing forces. Since lowintensity shocks would require relatively longer durations than high-intensity shock for intolerable severity values, the asymptotic behavior in an escape task should be related to shock intensity. More specifically, during a series of trials, the escape latency may be modified on each trial by a simple linear operator as follows:

$$
\mathrm{L}_{\mathbf{n}+1}=\mathrm{L}_{\mathbf{n}}+\alpha\left(\lambda_{\alpha}-\mathrm{L}_{\mathbf{n}}\right)
$$

$L_{n}$ is the expected escape latency on Trial $n, \lambda_{\alpha}$ is the asymptotic latency, and $\alpha$ is the rate of adjustment. Different intensities of shock led to different asymptotic latencies and rates of adjustment. Asymptotic latencies were estimated from the geometric mean of the last 10 trials of each block; the rates of approach to the asymptote were estimated from the second trial of a given intensity through the first trial in which the latency was within $5 \%$ of the asymptote. The method of estimation we used is described by Bush and Mosteller (1955, p. 59). The rate-of-adjustment values were .87 for the highintensity condition and .10 for the low-intensity condition. Thus

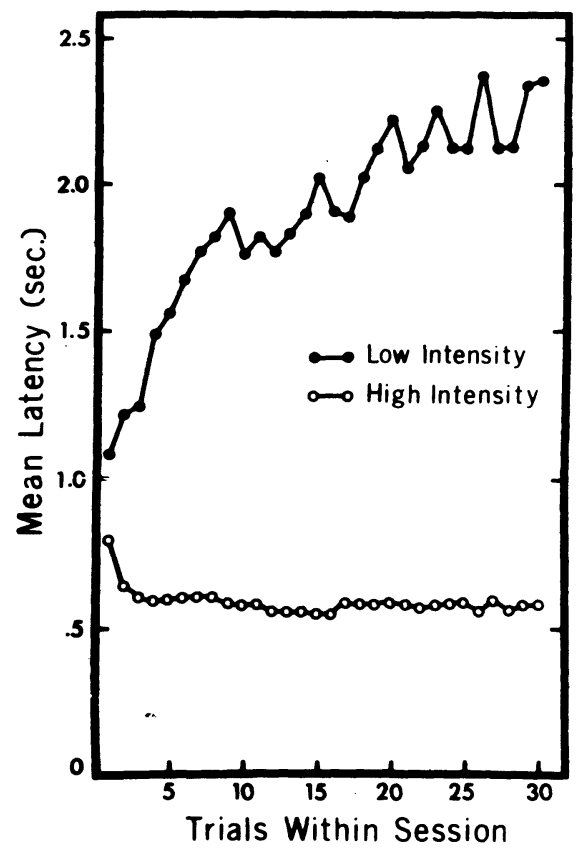

Figure 2. Geometric mean latency of escape for the four rats on the 30 trials within each high-intensity block and within each low-intensity block. 
the adjustment was over eight times as rapid for an increase in intensity as for a decrease in intensity.

\section{REFERENCES}

Boren, J. J., Sidman, M., \& Herrnstein, R. J. Avoidance, escape, and extinction as functions of shock intensity. Journal of Comparative and Physiological Psychology, 1959, 52, 420-425.

Bower, G. H., Fowler, H., \& Trapold, M. A. Escape learning as a function of amount of shock reduction. Journal of Experimental Psychology, 1959, 58, 482-484.

Bush, R. R., \& Mosteller, F. Stochastic models of learning. New York: Wiley, 1955.
Church, R. M., Raymond, G. A., \& Beauchamp, R. D. Response suppression as a function of intensity and duration of a punishment. Journal of Comparative and Physiological Psychoiogy, 1967, 63, 39-44.

Nation, J. R., Wrather, D. M., \& Mellgren, R. L. Contrast effects in escape conditioning of rats. Journal of Comparative and Physiological Psychology, 1974, 86, 69-73.

TRAPOLD, M. A., \& Fowler, H. Instrumental escape performance as a function of the intensity of noxious stimulation. Journal of Experimental Psychology, 1960, 60. 323-326.

(Received for publication January $30,1976$. ) 